\title{
Violência como gatilho para o adoecimento psíquico em mulheres na terceira idade
}

\author{
Violence as a trigger for psychic illness in third-age women \\ La violencia como detector de enfermedad psíquica em mujeres de tercera edad
}

Recebido: 04/06/2021 | Revisado: 14/06/2021 | Aceito: 23/06/2021 | Publicado: 04/07/2021

\author{
Rejane Mendes Oliveira \\ ORCID: https://orcid.org/0000-0003-3420-1209 \\ Faculdade de Ensino Superior do Piauí, Brasil \\ E-mail: rejanesilvamendes@ hotmail.com \\ Denise Martins da Costa e Silva \\ ORCID: https://orcid.org/0000-0003-1894-7166 \\ Faculdade de Ensino Superior do Piauí, Brasil \\ E-mail: denisemartins@grupomagister.com.br \\ Ruth Raquel Soares de Farias \\ ORCID: https://orcid.org/0000-0002-0988-0900 \\ Faculdade de Ensino Superior do Piauí, Brasil \\ E-mail: ruthraquelsf@gmail.com
}

\begin{abstract}
Resumo
O presente estudo trata de uma revisão de bibliográfica integrativa sobre a Violência como gatilho para o adoecimento psíquico em mulheres na terceira idade, tem como objetivo investigar a correlação entre a violência contra a mulher na terceira idade e o adoecimento psíquico. A violência contra o idoso refere-se a qualquer ação ou omissão realizada em local público ou privado que cause morte, lesão ou dor física ou psicológica. Os idosos se tornam vítimas fácies, muitas vezes por dependerem de seus familiares em inúmeros aspectos e as mulheres mais velhas são as mais vulneráveis à violência doméstica, os maus-tratos sofridos contribuem para seu adoecimento, entre eles o psíquico. $\mathrm{O}$ estudo buscou também caracterizar o envelhecimento feminino no Brasil; descrever a situação de violência contra a mulher na terceira idade; relacionar a violência contra a mulher na terceira idade e o adoecimento psíquico. Identificar e tratar as doenças causadas por essas violências é um dos desafios, considerando gênero e faixa etária. Para a pesquisa foi utilizado os bancos de dados da SCIELO, PUBMED e GOOGLE ACADÊMICO nos anos de 2010 a 2020 para a análise de dados. Os resultados apontam que a violência é um fator determinante para o adoecimento psíquico. Diante do exposto, conclui-se que em relação a questões específicas de saúde mental e violência doméstica na terceira idade, é necessário questionamentos, no intuito de tornar essa violência mais óbvia, sensibilizar os profissionais, e realizar pesquisas para problematizar a relação entre a violência e adoecimentos psíquico de mulheres idosas o que pode proporcionar inúmeras contribuições neste campo.
\end{abstract}

Palavras-chave: Idosos; Maus tratos; Saúde mental; Tipos de violência; Violência contra a mulher idosa.

\begin{abstract}
The present study deals with an integrative bibliographic review on Violence as a trigger for psychological illness in elderly women. It aims to investigate the correlation between violence against elderly women and mental illness. Violence against the elderly refers to any action or omission performed in a public or private place that causes death, injury or physical or psychological pain. Elderly people become easy victims, often because they depend on their family members in numerous aspects and older women are the most vulnerable to domestic violence, the mistreatment they suffer contributes to their illness, including the psychological one. The study also sought to characterize female aging in Brazil; describe the situation of violence against women in the elderly; relate violence against women in the elderly and mental illness. Identifying and treating the diseases caused by this violence is one of the challenges, considering gender and age group. For the research, the databases of SCIELO, PUBMED and GOOGLE ACADEMIC were used in the years 2010 to 2020 for data analysis. The results show that violence is a determining factor for mental illness. Given the above, it is concluded that in relation to specific issues of mental health and domestic violence in the elderly, it is necessary to ask questions in order to make this violence more obvious, sensitize professionals, and conduct research to problematize the relationship between violence and psychological illnesses of elderly women, which can provide numerous contributions in this field.
\end{abstract}

Keywords: Elderly; Mistreatment; Mental health; Types of violence; Violence against elderly women.

\section{Resumen}

El presente estudio trata de una revisión bibliográfica integradora sobre la Violencia como desencadenante de enfermedad psíquica en mujeres en la vejez, con el objetivo de investigar la correlación entre la violencia contra la mujer en la vejez y la enfermedad mental. La violencia contra las personas mayores se refiere a cualquier acción u omisión realizada en un lugar público o privado que cause la muerte, lesiones o dolor físico o psicológico. Las 
personas mayores se convierten en víctimas fáciles, muchas veces porque dependen de sus familiares en numerosos aspectos y las mujeres mayores son las más vulnerables a la violencia doméstica, el maltrato que sufren contribuye a su enfermedad, incluida la psíquica. El estudio también buscó caracterizar el envejecimiento femenino en Brasil; describir la situación de violencia contra la mujer en la vejez; relacionar la violencia contra la mujer en la vejez y la enfermedad mental. Identificar y tratar las enfermedades causadas por estas violencias es uno de los desafíos, considerando el género y el grupo de edad. Para la investigación se utilizaron para el análisis de datos las bases de datos de SCIELO, PUBMED y GOOGLE ACADÊMICO en los años 2010 a 2020. Los resultados muestran que la violencia es un factor determinante de la enfermedad psíquica. Teniendo en cuenta lo anterior, se concluye que, en relación a temas específicos de salud mental y violencia intrafamiliar en la vejez, es necesario plantear preguntas, con el fin de hacer más evidente esta violencia, sensibilizar a los profesionales y realizar investigaciones para problematizar la relación entre violencia y enfermedades psíquicas de las ancianas, que pueden aportar innumerables aportes en este campo.

Palabras clave: Anciano; Malos tratos; Salud mental; Tipos de violencia; Violencia contra las mujeres mayores.

\section{Introdução}

A pesquisa foi realizada sobre o tema "Violência como gatilho para adoecimento psíquico em mulheres da terceira idade", onde apresentara tipo de violência, características dos agressores, transtorno e as perdas socioemocionais de um grupo acima citado que abrange $30 \%$ da população brasileira e com uma escala crescente (IBGE, 2019). A compreensão do processo de envelhecimento da população feminina, diante do contexto de violência que assola a sociedade contemporânea, oportuniza aos profissionais de psicologia e aos demais profissionais, não só ter uma visão do problema social, mas promover orientações a mulheres idosas e intervenções que possam subsidiar dentre outras possibilidades, a desmistificação da violência como um ato normal.

A violência é um fenômeno que atinge as pessoas e a vida em sociedade Faleiros, Loureiro e Penso (2010, p.03) conceitua violência como: "Violência é um processo social relacional, complexo e diverso, que precisa ser entendido na estruturação da própria sociedade e das relações interpessoais, institucionais e familiares, inclusive de poder". De acordo com o citado, abre as discussões e reflexões: Como o Brasil tem lidado com o envelhecimento populacional, mais especificamente o feminino? Quais as políticas públicas de proteção das mulheres idosas? Mulheres idosas que foram vítimas de violências apresentam sequelas emocionais?

Foi observado que ainda há uma carência de publicações especificamente voltadas a essas temáticas, o que deixou uma lacuna, um amplo campo de pesquisa e contribuições científicas. Desse modo, outras questões, desdobramentos das questões anteriormente citadas, foram acrescidas: Nos casos de violências contra a mulher idosa, as vítimas formalizavam denúncia contra o agressor? As ocorrências contra as vítimas eram em decorrência da idade ou gênero? Havia sequelas psíquicas nas vítimas idosas após serem submetidas a um ato de violência? Quais as manifestações de violência contra a mulher idosa?

Dessa forma, esta pesquisa teve como objetivo geral: investigar a correlação entre a violência contra a mulher na terceira idade e o adoecimento psíquico. Especificamente visa: a) caracterizar o envelhecimento feminino no Brasil; b) descrever a situação de violência contra a mulher na terceira idade; c) relacionar a violência contra a mulher na terceira idade e o adoecimento psíquico. Com esses objetivos, esta pesquisa, torna público a violência privada contra mulher na terceira idade, despertar na sociedade acadêmica, psicólogas(o), profissionais atuantes na área da saúde, cuidadores e a todos que de forma direta ou indiretamente estão ligados a causa para um olhar cuidadoso e investigativo quanto ao índice crescente da violência contra a mulher idosa. Para o embasamento teórico do estudo contamos com autores como: Dalgalarrondo (2019), Bittar e Kohlsdorf (2013), Faleiros, Loureiro e Penso (2010), dentre outros.

Foram analisadas, a partir de uma revisão integrativa da literatura especializada na área, as manifestações da violência e as sequelas psíquicas ocorridas contra mulheres da terceira idade, objetivando caracterizar os principais transtornos psíquicos 
correlacionados à violência, além de descrever as características comuns dos agressores no contexto de violência contra mulher idosa.

Para a promoção da saúde mental deve-se empreender esforços para que as mulheres idosas se sintam mais conectadas e amparadas pelos apoiadores disponíveis em seu entorno social. Dessa forma, essa pesquisa traz uma contribuição para dar mais visibilidade científica para a temática, além de justificar-se pelas contribuições que a publicização referente ao adoecimento psíquico de mulheres na terceira idade decorrente da violência faz-se necessária para fortalecimento de ações estratégicas para o enfrentamento.

\section{Metodologia}

Esta pesquisa foi de cunho qualitativo, teve como objeto investigar a correlação entre a violência contra a mulher na terceira idade e o adoecimento psíquico de mulheres da terceira idade. Tratou-se de uma revisão bibliográfica integrativa, a partir da síntese de publicações das quais foi possível chegar a conclusões gerais acerca da violência contextualizada naquele universo particular da mulher na terceira idade, mais especificamente evidenciando-o em relação ao adoecimento psíquico.

Partiu-se de uma investigação teórica para o entendimento de conceitos citados pelos autores e a interface adoecimento psíquico, mulheres e terceira idade. Assim, considerado o entendimento, foi revelado essa integração acerca da temática tantas vezes negligenciada da pesquisa científica, mas que deve repercutir haja vista sua relevância para a sociedade.

A análise percorreu os seguintes passos: 1) formulação do problema; 2) avaliação dos dados coletados; 3) análise e interpretação desses dados; e 4) apresentação dos resultados.

O problema formulado foi: A violência apresenta-se como um gatilho para o adoecimento psíquico de mulheres da terceira idade. A partir desse problema, foi realizado o levantamento de pesquisas na internet nas seguintes bases de dados: Scielo (Scientific Eletronic Library on Line), Pubmed (National Library of Medicine) e Google acadêmico. Os descritores foram: violência contra a mulher, adoecimento psíquico e terceira idade.

Como critério de inclusão foram utilizados :artigos em português indexados em banco de dados, que precisariam ter concordância com os descritores já citados, foi realizando leituras cuidadosas dos respectivos resumos, para que fossem identificados e selecionados de acordo com a relevância para a pesquisa, depois de selecionados foi realizada a leitura integral dos artigos.

Estabeleceu-se um recorte temporal dos últimos 10 anos, ocorrendo exclusões de materiais como: artigos em outros idiomas, materiais nos quais as propostas não condiziam com a temática da pesquisa. O levantamento do material teve início no mês de agosto de 2020 findando no mês de janeiro de 2021, período no qual 45 artigos e 2 livros foram lidos e analisados na integra. Dentre esses 20 artigos não correlacionavam a violência a mulher idosa, 6 artigos eram de blogs não científicos e 9 foram com publicações com mais de 30 anos ficando fora dos critérios estabelecidos pela pesquisadora, ficando excluídos. Desse modo, 12 materiais foram incluídos nesta revisão integrativa. Os artigos estabeleciam relação com os descritores violência privada, característica dos agressores, adoecimentos psíquicos e dados relacionados a violência e a mulher idosa, totalizando assim o material de base para a pesquisa.

Com a seleção desses artigos, foi possível selecionar aqueles que correspondiam aos objetivos desta pesquisa, organizá-los a partir do quadro para analisar os conteúdos a partir da estruturação de categorias de análises.

\section{Resultados e Discussão}

O resultado total das buscas de artigos conforme as bases e dado e os critérios de inclusão podem ser vistos no fluxograma abaixo: 
Fluxograma 1: Artigos levantados nas bases de dados SCIELO, LILACS, PUBMED, GOOGLE ACADÊMICO.
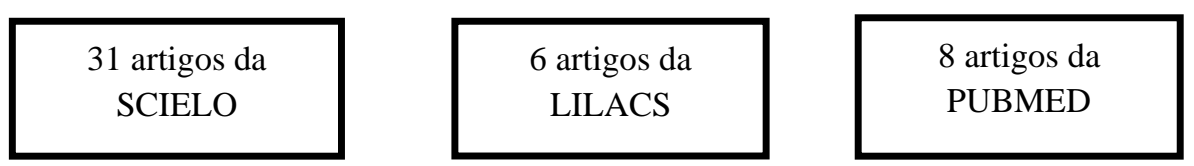

\section{2 livros GOOGLE ACADÊMICO}

Após utilizar os critérios de inclusão foram encontrados

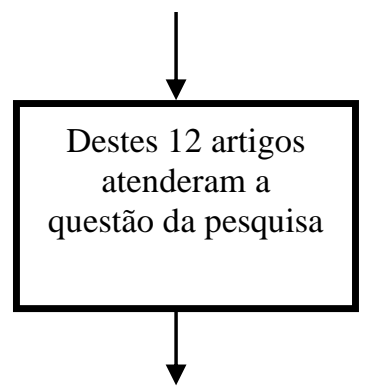

Depois de uma leitura seletiva apenas 12 trabalhos entre os anos de 2010 a 2021, foram relevantes e selecionados para a revisão integrativa

Fonte: Autores (2021).

Assim, com o objetivo de descrever sucintamente os artigos selecionados e que darão subsídio às discussões, a seguir tem-se o Quadro 1 trazendo informações importantes sobre cada artigo como: autor, ano, objetivo, resultados e conclusão:

Quadro 1: Elaboração de quadro sinótico de revisão bibliográfica integrativa relacionado à violência como gatilho para o adoecimento psíquico, no período de 2010 a 2020.

\begin{tabular}{|c|c|c|c|}
\hline Autor/ano & Objetivos & Resultados & Conclusão \\
\hline $\begin{array}{l}\text { Faleiros; Loureiro; } \\
\text { Penso (2010) }\end{array}$ & $\begin{array}{l}\text { Elaborar uma análise } \text { das } \\
\text { relações de violência na } \\
\text { família com enfoque da } \\
\text { história familiar das relações } \\
\text { intergeracionais e do } \\
\text { imaginário. }\end{array}$ & $\begin{array}{l}\text { Existe uma dificuldade de se } \\
\text { falar do problema no interior } \\
\text { das famílias, independente da } \\
\text { situação socioeconômica. }\end{array}$ & $\begin{array}{l}\text { Nas relações de violência contra } \\
\text { a pessoa idosa maior vitimização } \\
\text { são mulheres os agressores são na } \\
\text { maioria filhos e filhas, que varia } \\
\text { de simples ofensivas verbais até } \\
\text { agressões físicas e psicológicas, } \\
\text { considerada como um grande } \\
\text { problema social. }\end{array}$ \\
\hline $\begin{array}{l}\text { Ploner; Hoffann; } \\
\text { Baldissera (2014) }\end{array}$ & $\begin{array}{l}\text { Caracterizar as denúncias de } \\
\text { violência sofrida por idosos } \\
\text { que foram atendidos pelo } \\
\text { CREAS de Itajaí em } 2012 \text {. }\end{array}$ & $\begin{array}{l}\text { Denúncia por } r \text { demanda } \\
\text { espontânea foi } 63 \% \text { dos casos; } \\
\text { o tipo de violência } \\
\text { predominante foi } \\
\text { abandono/negligência }(42 \%) \text { as } \\
\text { mulheres foram as vítimas mais } \\
\text { acometidas }(60 \%) \text { que a faixa } \\
\text { etária da maior parte das } \\
\text { vítimas estava entre } 70 \text { e } 79 \\
\text { anos (40\%); que } 42 \% \text { das } \\
\text { vítimas recebia um salário } \\
\text { mínimo e que os filhos eram os } \\
\text { suspeitos pelas agressões em } \\
55 \% \text { dos casos. }\end{array}$ & $\begin{array}{l}\text { Conhecer as características das } \\
\text { denúncias de violência contra os } \\
\text { idosos mostrou ser necessário } \\
\text { para subsidiar pedidos de } \\
\text { ampliação e modificação das } \\
\text { políticas públicas de proteção e } \\
\text { assistência aos idosos. }\end{array}$ \\
\hline $\begin{array}{l}\text { Bittar; } \\
\text { (2013) }\end{array}$ & 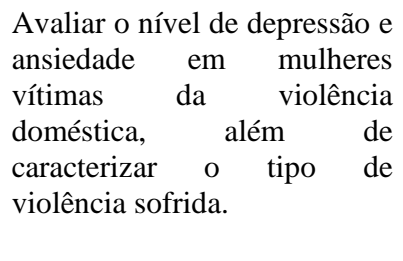 & $\begin{array}{l}\text { Foi observada correlação } \\
\text { positiva, moderada e } \\
\text { estaticamente significativa entre } \\
\text { as medidas de ansiedade e } \\
\text { depressão, além de múltiplas } \\
\text { formas de violência simultânea. }\end{array}$ & $\begin{array}{l}\text { A violência doméstica está } \\
\text { associada a uma percepção } \\
\text { negativa da saúde física e mental } \\
\text { da mulher, requerendo políticas } \\
\text { de atuação integrada que possam } \\
\text { possibilitar maneiras eficientes de } \\
\text { manejar este problema social. }\end{array}$ \\
\hline
\end{tabular}




\begin{tabular}{|c|c|c|c|}
\hline Almeida et al., (2015) & $\begin{array}{l}\text { Caracterizar o perfil } \\
\text { socioeconômico, pessoal e } \\
\text { familiar das idosas do "Clube } \\
\text { da Vovó", em Viçosa/MG, } \\
\text { além de identificar os tipos de } \\
\text { riscos sociais enfrentados por } \\
\text { elas associados a esse perfil. }\end{array}$ & $\begin{array}{l}\text { Destacou-se o número } \\
\text { significativo de octogenárias e } \\
\text { viúvas. Aspectos como a baixa } \\
\text { renda e a baixa escolaridade } \\
\text { foram encontrados. O estado de } \\
\text { saúde das idosas foi } \\
\text { majoritariamente avaliado como } \\
\text { bom. }\end{array}$ & $\begin{array}{l}\text { Esses fatores, associados à } \\
\text { percepção da velhice pelas } \\
\text { idosas, revelaram que o } \\
\text { envelhecimento feminino } \\
\text { acarreta consequências que } \\
\text { permitem inferir que elas estão } \\
\text { em potencial risco social. }\end{array}$ \\
\hline Silva; Dias (2016) & $\begin{array}{l}\text { Conhecer o } \\
\text { sociodemográfico } \\
\text { familiares agressores, os tipos } \\
\text { de violência impetradas e as } \\
\text { motivações para sua } \\
\text { ocorrência. }\end{array}$ & $\begin{array}{l}\text { O grau de escolaridade } \\
\text { predominante foi o ensino } \\
\text { médio } \\
\text { predominando a profissão de } \\
\text { doméstica. O grau de } \\
\text { parentesco predominante dos } \\
\text { agressores foi o de filhos } \\
\text { seguido de genros A renda } \\
\text { familiar predominante de dois } \\
\text { salários mínimos. }\end{array}$ & $\begin{array}{l}\text { A violência contra pessoa idosa é } \\
\text { uma demanda crescente em } \\
\text { virtude do aumento dessa parcela } \\
\text { populacional. Porém, trata-se de } \\
\text { um mal que necessita ser } \\
\text { extinguido da sociedade. O perfil } \\
\text { do abusador de idosos por ordem } \\
\text { de frequência, tem em primeiro } \\
\text { lugar, os filhos; em segundo } \\
\text { lugar, as noras e os genros e, em } \\
\text { terceiro, o cônjuge. }\end{array}$ \\
\hline Rocha (2017) & $\begin{array}{l}\text { Abordar a questão específica } \\
\text { da violência contra a mulher } \\
\text { idosa, apontando nuances } \\
\text { acerca da situação atual, } \\
\text { carreando dados estatísticos, } \\
\text { assim como a legislação } \\
\text { existente e políticas públicas } \\
\text { afetas ao tema. }\end{array}$ & $\begin{array}{l}\text { A amostra foi composta por } 31 \\
\text { estudos, sendo a maioria } \\
\text { reflexões teóricas, descritivos, } \\
\text { sobre violência doméstica, com } \\
\text { enfoque às vítimas e abordando } \\
\text { temas relacionados com a } \\
\text { prevalência ou incidência e } \\
\text { intervenções que podem ser } \\
\text { realizadas por profissionais de } \\
\text { saúde. Trataram ainda de } \\
\text { estudos de percepção de grupos, } \\
\text { vítimas ou profissionais. }\end{array}$ & $\begin{array}{l}\text { Políticas públicas de proteção aos } \\
\text { direitos da mulher vêm sendo } \\
\text { desenvolvidas ao longo dos anos, } \\
\text { em especial com legislação } \\
\text { aprimoramento da le } \\
\text { pertinente e de normas e } \\
\text { princípios para o enfrentamento } \\
\text { da violência contra a mulher. }\end{array}$ \\
\hline Mota (2017) & $\begin{array}{l}\text { Analisar como a violência } \\
\text { contra a mulher se relaciona } \\
\text { com a situação de sofrimento } \\
\text { psíquico de mulheres usuárias } \\
\text { da atenção primária à saúde } \\
\text { em Recife }\end{array}$ & $\begin{array}{l}\text { Foi possível perceber que as } \\
\text { questões que envolvem o } \\
\text { sofrimento psíquico das } \\
\text { mulheres surgem na atenção } \\
\text { primária de diversas formas, } \\
\text { seja na reprodução da lógica, } \\
\text { por profissionais e usuárias, de } \\
\text { medicalização do sofrimento, } \\
\text { na dificuldade de relatar } \\
\text { questões entendidas pelas } \\
\text { mulheres como mais pessoais } \\
\text { aos profissionais, nos diferentes } \\
\text { casos que expressam situações } \\
\text { de opressão, com o surgimento } \\
\text { de queixas como depressão e } \\
\text { tentativas e/ou desejo de } \\
\text { suicídios, ou ainda no não } \\
\text { reconhecimento da unidade de } \\
\text { saúde da família como instância } \\
\text { primeira para o atendimento às } \\
\text { situações de violência contra as } \\
\text { mulheres. }\end{array}$ & $\begin{array}{l}\text { O sofrimento psíquico tem sido } \\
\text { cada vez mais experimentado } \\
\text { pelas mulheres, tendo sido } \\
\text { percebido em todos os relatos de } \\
\text { formas distintas, a partir das } \\
\text { singularidades dos casos, dos } \\
\text { diversos de tipos de violência } \\
\text { contra as mulheres e das } \\
\text { desiguais relações sociais de } \\
\text { gênero, classe raça. Por fim, o } \\
\text { desenvolvimento deste trabalho } \\
\text { possibilitou compreender o } \\
\text { quanto ainda se faz necessário } \\
\text { visibilizar tais relações, } \\
\text { principalmente no que diz } \\
\text { respeito às interconexões entre os } \\
\text { campos. }\end{array}$ \\
\hline Diel; Barbini (2018) & $\begin{array}{l}\text { Analisar as expressões da } \\
\text { violência familiar contra a } \\
\text { pessoa idosa e as perspectivas } \\
\text { de seu enfrentamento, a partir } \\
\text { de pesquisa realizada no } \\
\text { Centro de Referência } \\
\text { Especializado de Assistência } \\
\text { Social (CREAS) de São } \\
\text { Leopoldo, Rio Grande do Sul. }\end{array}$ & $\begin{array}{l}\text { Os resultados revelaram } \\
\text { marcadores geracionais e de } \\
\text { gênero significativos: as } \\
\text { principais vítimas foram } \\
\text { mulheres de idade avançada, } \\
\text { viúvas, que, apesar de relativa } \\
\text { autonomia econômica, } \\
\text { dependiam de cuidados de } \\
\text { saúde, a cargo de suas famílias, } \\
\text { essas, por sua vez, as principais }\end{array}$ & $\begin{array}{l}\text { A pesquisa faz-nos refletir sobre } \\
\text { o fato de que muitas pessoas } \\
\text { idosas não possuem o } \\
\text { conhecimento de como/que } \\
\text { forma denunciar. Muitas, } \\
\text { inclusive, não acreditam que têm } \\
\text { os seus direitos violados, já que } \\
\text { são vítimas de seus familiares - } \\
\text { geralmente, o(a) seu/sua filho(a) - } \\
\text { e sustentam que as questões } \\
\text { familiares "devem ser resolvidas }\end{array}$ \\
\hline
\end{tabular}




\begin{tabular}{|c|c|c|c|}
\hline & & agressoras. & $\begin{array}{l}\text { em casa" e que o dinheiro de sua } \\
\text { aposentadoria é da família, ou } \\
\text { seja, todos podem dele fazer uso. } \\
\text { Também defendem que uma } \\
\text { palavra grosseira ou de baixo } \\
\text { calão é proferida, às vezes, mas } \\
\text { foi ela quem educou o(a) filho(a) } \\
\text { e que "não soube lhe dar limite. }\end{array}$ \\
\hline Matos et al., (2019) & $\begin{array}{l}\text { Traçar o perfil do agressor de } \\
\text { pessoas idosas atendidas em } \\
\text { um centro de referência em } \\
\text { geriatria e gerontologia do } \\
\text { Distrito Federal, Brasil, entre } \\
\text { os anos de } 2008 \text { a } 2018 \text {. }\end{array}$ & $\begin{array}{l}\text { Foram analisados } 111 \text { casos. Os } \\
\text { filhos foram os principais } \\
\text { agressores }(72 \%) \text {, com } \\
\text { prevalência do sexo masculino } \\
(62 \%) \text { e faixa etária de } 51 \text { a } 60 \\
\text { anos }(37 \%) \text { Os idosos } \\
\text { agredidos eram } \\
\text { predominantemente mulheres } \\
(72 \%) \text {, quase metade continham } \\
\text { entre } 81 \text { a } 90 \text { anos, seguidos } \\
\text { daqueles com } 71 \text { a } 80 \text { anos } \\
(39 \%) \text {. } 16 \% \text { dos idosos } \\
\text { residiam com os filhos ou } \\
\text { familiares próximos. Os } \\
\text { principais tipos de violência } \\
\text { evidenciados foram a } \\
\text { negligência }(56 \%) \text { e a violência } \\
\text { psicológica }(29 \%) \text {, neste estudo } \\
\text { a violência física representou } \\
8 \%\end{array}$ & $\begin{array}{l}\text { O estudo do perfil do agressor e } \\
\text { da pessoa idosa agredida reforçou } \\
\text { a necessidade de focalização das } \\
\text { ações dentro dos arranjos } \\
\text { familiares. Acredita-se que } \\
\text { investigações que abordem a } \\
\text { figura de quem pratica a } \\
\text { violência possam contribuir no } \\
\text { fomento de políticas públicas em } \\
\text { saúde e contribuições para a } \\
\text { prática clínica geriátrica e } \\
\text { gerontológica de combate à } \\
\text { violência contra a pessoa idosa. }\end{array}$ \\
\hline $\begin{array}{l}\text { Maximiano-Barreto et } \\
\text { al., (2019) }\end{array}$ & $\begin{array}{l}\text { Levantar a temática da } \\
\text { feminização da velhice, um } \\
\text { fenômeno resultante da } \\
\text { transição demográfica, no } \\
\text { qual o número de mulheres } \\
\text { com idade maior ou igual à } 60 \\
\text { anos se sobressai ao } \\
\text { contingente masculino. }\end{array}$ & $\begin{array}{l}\text { A variável gênero atua como } \\
\text { fator determinante, tornando-se } \\
\text { necessário estudos que se } \\
\text { voltem para tal realidade e } \\
\text { busquem alternativas que } \\
\text { possam solucionar desfechos } \\
\text { negativos enfrentados pelas } \\
\text { mulheres idosas. }\end{array}$ & $\begin{array}{l}\text { A dimensão psicossocial na } \\
\text { abordagem sobre a feminização } \\
\text { da velhice, trata-se de um } \\
\text { fenômeno multifacetado } \\
\text { incidente sobre uma parcela da } \\
\text { população muito heterogênea e } \\
\text { que cresce exponencialmente - a } \\
\text { de mulheres idosas. }\end{array}$ \\
\hline $\begin{array}{l}\text { Paulo; Alves; Machado } \\
\text { (2019) }\end{array}$ & $\begin{array}{l}\text { Discutir os aspectos } \\
\text { relacionados à violência } \\
\text { psicológica sofrida pela } \\
\text { pessoa idosa, o seio } \\
\text { intrafamiliar como principal } \\
\text { causador desse tipo de } \\
\text { violência e os impactos } \\
\text { causados na vida do idoso. }\end{array}$ & $\begin{array}{l}\text { Estudos mostram que o } \\
\text { sofrimento mental provocado } \\
\text { por esse tipo de maltrato } \\
\text { contribui para processos } \\
\text { depressivos e autodestrutivos, } \\
\text { por vezes levando à ideação, } \\
\text { tentativas de suicídio ou mesmo } \\
\text { ao suicídio consumado. }\end{array}$ & $\begin{array}{l}\text { Apesar do envelhecimento } \\
\text { humano estar em crescente } \\
\text { aumento, estão surgindo fatores } \\
\text { negativos em relação a esta } \\
\text { população na atualidade. Dois } \\
\text { desses fatores negativos é a } \\
\text { violência psicológica } \\
\text { intrafamiliar praticada contra o } \\
\text { idoso e o despreparo da família, } \\
\text { da sociedade, das instituições e } \\
\text { do estado em como trabalhar com } \\
\text { esta população. }\end{array}$ \\
\hline Dalgalarrondo (2019) & \begin{tabular}{lr} 
Apresentar & \multicolumn{2}{c}{ conceitos } \\
descritivos da tradição das \\
psicopatologias a estudantes e \\
profissionais além de \\
conhecimentos científicos \\
contemporâneos sobre a \\
mente humana e seus \\
transtornos.
\end{tabular} & $\begin{array}{l}\text { Considerando sistemas de } \\
\text { diagnóstico de transtornos } \\
\text { mentais da atualidade DSM e } \\
\text { CID são apresentados conceitos } \\
\text { psicopatológicos diretrizes e } \\
\text { critérios diagnósticos sempre } \\
\text { que possível correspondentes as } \\
\text { versões mais recentes. }\end{array}$ & $\begin{array}{l}\text { Ampliação da discussão sobre } \\
\text { Psicopatologias e semiologia dos } \\
\text { transtornos mentais apresentando } \\
\text { a relação entre os conceitos da } \\
\text { psicopatologia, mente humana e } \\
\text { seus transtornos. }\end{array}$ \\
\hline
\end{tabular}

Fonte: Autores (2021).

Por opção didática a pesquisa foi dividida em categorias temáticas, tendo como foco como ocorre o processo de envelhecimento feminino no Brasil e as possíveis consequências psíquicas e socioemocionais, diante da violência de gênero na senilidade ressaltando sobre os tipos e o perfil dos agressores. 


\section{Feminização da velhice no Brasil}

De acordo com os dados do Instituto Brasileiro de Geografia e Estatística (IBGE, 2018), a população feminina do Brasil engloba um número crescente na população da terceira idade considerada ativa. Em outras pesquisas realizadas são citadas que "no Brasil, assim como em diversos países em desenvolvimento, o aumento da população idosa vem ocorrendo de forma muito rápida e progressiva, sem a correspondente modificação nas condições de vida" (Dawalibi, 2013, p.393). Com relação ao aumento significativo de mulheres que atingiram a terceira idade as informações abaixo revelam:

As principais causas para essa tendência de envelhecimento seriam o menor número de nascimentos a cada ano, ou seja, a queda da taxa de fecundidade, além do aumento da expectativa de vida do brasileiro. Segundo as Tábuas Completas de Mortalidade, do IBGE, quem nasceu no Brasil em 2017 pode chegar, em média, a 76 anos de vida. Na projeção, quem nascer em 2060 poderá chegar a 81 anos. Desde 1940, a expectativa já aumentou 30,5 anos. Diante do contexto de envelhecimento populacional brasileiro, um grupo específico chama atenção: as mulheres (IBGE, 2018).

As projeções do Instituto Brasileiro de Geografia e Estatística (IBGE, 2018), é que o índice de envelhecimento (relação entre a porcentagem de idosos e jovens) teve um aumento em quarenta e três, dezenove por cento (43,19\%) no ano de dois mil e dezoito; até o ano de dois mil e sessenta (2060); esse aumento será de cento e setenta e três vírgula quarenta e sete por cento $(173,47 \%)$.

O contingente feminino é mais expressivo quanto mais idoso for o segmento. As mulheres idosas têm probabilidade maior de enviuvar e ficar em situação socioeconômica desvantajosa, pois a maioria nunca fez trabalho remunerado durante sua vida adulta. Além disso, embora vivam mais que os homens, as idosas passam por um período maior de debilidade física antes de morte do que eles. Por outro lado, elas participam mais que os homens de atividades fora de seus domicílios, como, por exemplo, participar de organizações e grupos de idosos, estudar e viajar (Camargo, 2014).

A "autonomia é uma dimensão feminina que as mulheres mais velhas emprestam a si mesmas" (Almeida; Oliveira, 2013, p.309). Neste sentido, fica percebido a identidade de mulher que atravessa primordialmente a produção e a performance corporal que ressignificar o tempo é manter o controle da vida através de atividades como ir ao cinema, praticar esportes, viajar e se relacionar amorosamente, potencializando a sua feminilidade seu jeito "faceira.

As mulheres constituem a maioria da população da terceira idade em todo o mundo, estima-se que as mulheres vivam em média 5 a 7 anos a mais que homens em todas as regiões do mundo. No entanto, analisando esses dados de outro ângulo, fica claro que maior expectativa de vida não é sinônimo de longa duração, as mulheres acumularam condições desfavoráveis como violência, discriminação, baixa escolaridade, dependência financeira, entre outros aspectos negativos o que demanda, portanto, mais recursos externos (Almeida et al., 2015).

Reforça-se que tal posicionamento apresentando, ou seja, os fatores, estão diretamente relacionados ao desenvolvimento do comportamento violento, como a cultura duradoura da subordinação feminina ao masculino, a idealização do amor romântico fortemente inspirado pela mídia e de pouco significado, nesta perspectiva é relevante que o estado se posicione e busque efetivar intervenções sobre os crimes contra as mulheres (Bittar; Kohlsdorf, 2013).

É preciso ressaltar que a feminização da velhice, como um fenômeno entre a população idosa, as mulheres são mais dominantes do que os homens, a proporção de sexos da população idosa caiu significativamente, constituindo uma significativa população feminina, porém o envelhecimento da população trouxe uma série de desafios que precisam da atenção de todos, principalmente a partir das situação que podem ocorrer, neste sentido o estado deve implementação de políticas públicas para o prevenção e cuidado desta demanda. (Maximiano-Barreto et al., 2019).

As políticas públicas são ferramentas de cuidado, haja vista que a violência contra a mulher é um problema de grande incidência, expressando muitas vezes uma relação de poder muitas vezes, a mulher, submissa, sofre vários tipos da violência doméstica, entre quais existem a violência física, sexual, moral, psicológica e patrimonial, que costumam ocorrer 
frequentemente dentro de casa, sendo praticado pelo companheiro, marido, namorado, amante ou ex companheiros, filhos os que a torna mais vulnerável a estas práticas.

\section{A violência na perspectiva sócio-histórica e o baixo índice de denúncias contra os agressores}

No contexto histórico é sabido que as mulheres viveram em situação de violência, submissão, maus-tratos, e tais situações eram admitidas. Mesmo detentoras de alguns direitos conquistados a passos lentos, muitas mulheres ainda vivem em situação de submissão no imaginário masculino mulheres são suas posses, situação que gera a violência doméstica, seja ela física, psicológica ou moral (Matos et al., 2019).

A condição secundária dada a mulher, vista como um objeto, dependente em inúmeras situações (afetiva, financeira, emocional) do homem, são fenômenos que contribuem para o entendimento das poucas denúncias dos agressores. No que diz respeito a violência contra a mulher na terceira idade. Almeida e Oliveira (2013, p. 318) observam que comportamentos arraigados na cultura da violência urbana têm contribuído para o aumento dos crimes contra esta demanda:

[...] juntamente com inúmeras mulheres, tentamos entender nossa posição e mudá-la. Progressivamente nos demos conta das injustiças sexuais existentes nas instituições econômicas, sociais e políticas, e, ao mesmo tempo, estamos procurando meios para combatê-las.

A violência de gênero está concentrada nas agressões individuais que vão além do nível social e, em suma, reflete a dominação de um grupo e a subordinação de outro. Estudos apontam para a predominância do fenômeno da violência doméstica e dos seus fatores de risco, os valores autoritários e patriarcais, a violência como meio de resolver diferenças, etnias, a valorização da violência no desenvolvimento do papel masculino, a permissividade da violência entre os casais, a impulsividade, o álcool e as drogas e, até mesmo, as experiências do casal durante a infância e que envolvia a violência dos seus pais, tudo isso pode ser considerado como aspectos condicionantes para a prática da violência doméstica (Santos; Izulmino, 2014). A mulher idosa torna-se vítima da violência privada por serem julgadas como frágil, incapaz, velhas:

"O gênero, portanto, é uma noção que não abrange apenas o domínio do literário, a expressão de um enunciado, o significado de uma palavra, aqui é um convite para um repensar nos costumes e convenções, o aceito e o interdito, dores e prazeres, amor e ódio, tristezas e alegrias" (Almeida; Oliveira, 2013, p. 318).

O fato de as mulheres possuírem características biológicas diferentes dos homens não deve servir como justificativa para se manter uma relação de desigualdade entre ambos, as diferenças supõem outra face da identidade, onde os eixos de distribuição de conquista e poder se dão através das dessemelhanças referentes a gênero, etnia e classe, admitindo-se uma essência diferenciada entre homens e mulheres.

Mulheres idosas são as maiores vítimas de violência, resultado do machismo considerando a dominação e submissão da mulher idosa, todavia é importante frisar que tal ação no âmbito intrafamiliar vai contra a dinâmica familiar, haja vista que se pressupõe que este espaço é comprometido e compromissada com outro, pois possui laços de parentesco e afetivos como aspectos fortalecedores de proteção (Faleiros; Loureiro; Penso, 2019).

Esse tipo de violência manifesta-se também através da desvalorização das aposentadorias, do desrespeito nas filas de bancos, no transporte público, na negação dos direitos à saúde, na omissão dos poderes públicos quanto a políticas e programas 
de proteção específica para essa população, também conhecida como violência simbólica ${ }^{1}$, as mulheres na terceira idade são acometidos por serem consideradas frágeis, "presa-fácil".

É necessário apoiar e compreender as vivências das vítimas para obter informações, valorizar e fomentar a resistência ativa e a condenação dos abusos sofridos. Na repetição destes ciclos de violência, aumenta a tolerância das mulheres e gera-se um sentimento de normalidade, a naturalização da violência está diretamente relacionada à cultura patriarcal organizada por nossa sociedade (Bittar; Kohlsdorf, 2013).

Os ciclos da violência são recorrentes devido a vários fatores: dependência financeira e emocional, mudança nos sentimento de culpa, seja através de uma declaração clara ao parceiro (como se o agredissem por culpa), seja através a crença na fé, da culpa por não acreditar ter desempenhado o papel de mulher corretamente, pois no imaginário social a responsabilidade pelo bom desenvolvimento da relação conjugal é da mulher (Ibidem, 2013).

Considerando a denúncia a agressores, observa-se que a violência doméstica é geralmente é subnotificada, tal fenômeno ocorre principalmente ocorre devido problemas socioeconômicos, dificuldade que surgem e a ausência de conhecimento sobre velhice, o conflito pode começar nas dificuldades e despreparo da família que constitui a principal fonte provedora de cuidados à pessoa idosa (Matos, 2019).

\section{Categorização da violência}

Encarar a violência como adoecimento e efetivamente combatê-la como tal é essencial para o sucesso da proteção dos indivíduos, frente às agressões sofridas pelas mulheres idosas, os quadros abaixo apresentam a categorização da violência e a identificação dos principais tipos de violência que a mulher idosa pode sofrer, com o intuito de entender como estes ocorrem e por que a cada dia os números de violência crescem.

Quadro 2: categorização da violência.

\begin{tabular}{|l|l|l|}
\hline \multicolumn{1}{|c|}{ Estrutural } & \multicolumn{1}{|c|}{ Interpessoal } & \multicolumn{1}{c|}{ Institucional: } \\
\hline $\begin{array}{l}\text { Expressa nas desigualdades sociais } \\
\text { naturalizadas nas vivências de } \\
\text { pobreza, miséria e discriminação; }\end{array}$ & $\begin{array}{l}\text { Atualizada nas relações sociais } \\
\text { cotidianas e intergeracionais; }\end{array}$ & $\begin{array}{l}\text { Reproduzida na aplicação ou omissão } \\
\text { na gestão das políticas sociais, dos } \\
\text { serviços de assistência pública e } \\
\text { privada, nas relações assimétricas de } \\
\text { poder, de domínio, de menosprezo e } \\
\text { de discriminação }\end{array}$ \\
\hline
\end{tabular}

Fonte: Autores (2021).

\footnotetext{
${ }^{1}$ Violência simbólica é um conceito social elaborado pelo sociólogo francês Pierre Bourdieu, o qual aborda uma forma de violência exercida pelo corpo sem coação física, causando danos morais e psicológicos. https://pt.wikipedia.org/wiki/Viol\%C3\%AAncia_Simb\%C3\%B3lica. Acesso em: 20 de abr. 2021.
} 
Quadro 3: identificação dos principais tipos de violência.

\begin{tabular}{|l|l|}
\hline $\begin{array}{l}\text { Abuso físico, violência física ou maus- } \\
\text { tratos físicos }\end{array}$ & $\begin{array}{l}\text { refere-se ao uso da força física para compelir os idosos a fazerem o que } \\
\text { não desejam, para feri-los, provocar-lhes dor, incapacidade ou morte. }\end{array}$ \\
\hline $\begin{array}{l}\text { Abuso psicológico, violência psicológica } \\
\text { ou maus-tratos psicológicos }\end{array}$ & $\begin{array}{l}\text { corresponde a agressões verbais ou gestuais com o objetivo de aterrorizar } \\
\text { os idosos, humilhá-los, restringir sua liberdade ou isolá-los do convívio } \\
\text { social. }\end{array}$ \\
\hline Abuso sexual ou violência sexual & $\begin{array}{l}\text { referida ao ato ou ao jogo sexual de caráter homo ou } \\
\text { heterorrelacional, utilizando pessoas idosas, que visam a obter excitação, } \\
\text { relação sexual ou práticas eróticas por meio de aliciamento, violência física } \\
\text { ou ameaças. }\end{array}$ \\
\hline $\begin{array}{l}\text { Abuso financeiro e econômico ou violência } \\
\text { patrimonial }\end{array}$ & $\begin{array}{l}\text { consiste na exploração imprópria ou ilegal dos idosos ou ao uso não } \\
\text { consentido por eles de seus recursos financeiros e patrimoniais. }\end{array}$ \\
\hline Abandono & $\begin{array}{l}\text { manifestado na ausência ou deserção dos responsáveis } \\
\text { governamentais, institucionais ou familiares de prestarem socorro a uma } \\
\text { pessoa idosa que necessite de proteção. }\end{array}$ \\
\hline Negligência & $\begin{array}{l}\text { diz respeito a recusa ou omissão de cuidados devidos e necessários aos } \\
\text { idosos, por parte dos responsáveis familiares ou institucionais. }\end{array}$ \\
\hline Autonegligência ou violência auto infligida & $\begin{array}{c}\text { relativo à conduta da pessoa idosa que ameaça sua própria saúde ou } \\
\text { segurança, pela recusa de prover os cuidados necessários a si mesma. }\end{array}$ \\
\hline
\end{tabular}

Fonte: Autores (2021).

Neste sentido e conforme os quadros apresentados, definir categorias e tipologia permite compreender a situação dessa violência. Neste sentido as violências podem ser: violência física que está muitas vezes relacionada aos maus tratos físicos onde a pessoa idosa realiza algo que não deseja, a psicológica que está relacionada a agressões verbais e gestuais, a financeira que é explorar e se apropriar de forma ilegal dos bens, sejam eles materiais ou financeiros, o abuso sexual que é a violação do corpo, toque sem permissão, e a negligência que configura-se como omissão dos cuidados por parte das pessoas responsáveis (Ploner; Hoffamann; Baldissera, 2014).

Observa-se que os tipos de violência sofridos pelas mulheres idosas são múltiplos uma idosa pode apresentar dois ou mais tipos de violência podendo ela ser física psicológica negligência abandono violência patrimonial. As inúmeras tipologias de violências contribuem significativamente para o adoecimento da pessoa idosa, umas das principais é a violência psicológica que está presente em todas as formas de violência praticada contra pessoa idoso (Diel; Barbiani, 2018).

Ao longo dos anos, as políticas públicas de proteção aos direitos das mulheres foram formuladas, principalmente com o aprimoramento da legislação, normas e princípios pertinentes ao combate à violência contra as mulheres tais ferramentas são relevantes principalmente quando é de conhecimento que a "violência doméstica e abuso sexual, padrões conservadores de gênero e sofrimento mental (Rocha, 2017, p.63).

Independentemente do tipo de violência, as mulheres apresentam diversos sintomas físicos, tais como: dor de cabeça, dor, coração, tontura, desconforto, hematomas, fraturas, doenças gastrointestinais, dores musculares e inespecíficas em várias partes do corpo, emagrecimento ou peso Aumentos de perda, hematomas, escoriações, inflamação, desconforto difícil de localizar e diagnosticar, dor pélvica, infecção do trato urinário, gravidez indesejada, aborto espontâneo, doença psicossomática, doença mental ou comportamento compulsivo (Bittar; Kohlsdorf, 2013).

\section{Perfil dos agressores}

Em exame da relação entre o suspeito da violação e a vítima, verifica-se que a maioria das violências são realizadas por pessoas do convívio familiar ou próxima à vítima, convivendo com os seus agressores, seus direitos são violado no entanto por uma questão cultural vergonha em denunciar os agressores é muito difícil para elas, ficando subnotificado o número de casos em um número real pode ser ainda maior, que por muito tempo houve certa dificuldades mesmo com limitações foi 
possível traçar perfil dos agressores. Em termos percentuais, aponta-se que $65 \%$ dos suspeitos são filhos(a) da vítima, enquanto 9\% dos suspeitos são netos, $5 \%$ são genros ou noras e 4\% (IBGE, 2019).

Considerando os dados apresentados e no intuito de reforçar o enunciado anterior, afirma-se que o perfil da vítima que agride mulheres idosas é predominantemente o filho (sexo masculino) sendo a violência física a mais praticada, porém é relevante ressaltar que ao momento que se pratica violência física a violência psicológica está sendo realizada e tal ação contribui para incidência crescente do aumento de doenças na velhice afetando a qualidade de vida desses indivíduos considerando que são vítimas frequentes de agressão por tempo prolongado (Silva; Dias, 2016).

Com relação aos fatores de risco que contribuem para definir o perfil dos agressores a idosos estudos apontam que são definidos pela por fatores como: dependência econômica, geralmente por indivíduos que não possui idade superior 49 anos, desempregados, que vivem em situações de precariedade, dependentes de substancias psicoativas licitas e ilícitas, tais elementos são usados como justificativa para agressão, ao sujeito mais frágil no cenário familiar (Faleiro; Loureiro; Penso, 2019).

\section{Manifestações do transtorno de estresse pós-traumáticos}

Dentre os diversos tipos de violência contra o idoso, é necessário destacar um tipo específico de violência, raramente percebido e notificado, que é a violência psicológica, pois ocorre de forma discreta e oculta nas relações interpessoais. Esta violência pode estar se tornando uma das piores violências contra a pessoa idosa, considerando que podem se tornar os precursores de vários outros atos de violência e rompe com o direito a dignidade humana e de uma população envelhecida com saúde (Paulo; Alves; Machado, 2019)

No que diz respeito às mulheres, compreendem-se que contextos de vulnerabilidade e de violência são frequentemente e presentes nas situações que articulam as desigualdades sociais de gênero e do sofrimento psíquico. O que requer uma compressão acerca da violência também como questão de saúde pública e de demandas para o campo da saúde mental (Mota, 2017).

Para o entendimento do comportamento de refutação das mulheres idosas em denunciar seus agressores se faz necessário explanar os conceitos do TEPT ${ }^{2}$ (transtorno de estresse pós-traumático), medo social, ansiedade, depressão. Eventos pós-traumático podem converter-se ao TEPT em mulher idosa que estão submetidas a um ambiente hostil e que convivem com o agressor na mesma residência, sob violência psicológica, física, violação sexual, a um período prolongado, podem desencadear nas vítimas comportamento de esquiva, estas recusam a falar ou mesmo lembrar dos abusos sofrido, tal comportamento inconsciente traz a vítima um certo conforto mental, é importante que se entenda TEPT para um planejamento de escuta eficaz a vítimas aqui como objeto de estudo as mulheres idosas (Dalgalarrondo, 2019).

O TEPT é um transtorno com um forte componente de ansiedade que se transforma quando um indivíduo é exposto a uma ou mais ameaças extremas, trauma e eventos como, como estupro, sequestro, assalto, homicídio, incidente de guerra, entre outros, se caracteriza por lembranças ou recordações vividas que invadem a consciência do indivíduo que passou pelo trauma, e são acompanhados por emoções fortes e profundas, com ansiedade, medo e ou/horror e sensações físicas marcantes, ocorre de forma recorrente, revivendo as emoções de quando se experimentou o evento traumático (Dalgalarrondo, 2019).

A violência doméstica existe na vida diária das mulheres e nos serviços de saúde, a necessidade de cuidado está se tornando cada vez mais óbvia devido aos problemas psicossociais que ela produz, portanto, intervenções psicossociais eficazes que podem resolver a dor são necessárias para combater o sofrimento psíquico, que podem provocar doenças psicossomáticas diversas nas mulheres, com prevalência de quadros de depressão (Mota, 2017).

\footnotetext{
${ }^{2}$ TEPT é "uma psicopatologia que tem seu desenvolvimento a partir de um estimulo estressor, seja ele real ou imaginário, porém com impacto emocional forte o bastante para causar sofrimento psicológico e neurobiológico" (Knapp; Caminha ,2003, p. 31).
} 
Os sintomas psicológicos de mulheres que sofrem violência quase sempre são depressão, síndrome de estresse póstraumático, ansiedade, fobia, frustração, irritabilidade, transtorno do pânico, perigo iminente, ideação suicida, tentativa de suicídio, homicídio, baixa autoestima, intrínseco, complexo de inferioridade, insegurança, vergonha, isolamento social, inaceitável, tomada de decisão, dependência extrema, fumo, bebida, desatenção.

\section{Medo social}

É importante entender que o medo faz parte da filogenética do indivíduo, preparando-o para fuga, ataque, sendo uma característica universal de muitas espécies, Dalgalarrondo (2019, p. 165) nos diz: "medo é um estado de progressiva insegurança e angustia, de impotência e invalidez crescente ante a impressão iminente de que sucedera algo que o indivíduo quer evitar".

Diante do contexto da violência o medo social é produto de uma sociedade violenta e das formas como se constroem as relações de poder e as formas de sociabilidade. Entende-se que diante de atos abruptos a mulher tem uma reação típica de recuar, de não reagir, o que é comum, no entanto, após o ato esta passa mais tempo com medo. Dalgalarrondo (2019, p. 163) ainda destaca o medo em seis (6) fases, de acordo com o grau de extensão e intensidade, que são: prudência, cautela, alarme, ansiedade, pânico (medo intenso) e terror (medo intensíssimo). Nas análises patológicas todas as características e conceitos do medo e o quanto em excesso, pode ser prejudicial a uma pessoa. Segundo Eckert (2016, p. 2-37), no contexto social:

Os medos narrados e decifrados, que vem afetando as pessoas em sua existência, dando novos ritmos e sentidos ao seu cotidiano, mudando a arquitetura de suas casas, mudando trajetos e formas de ocupar a cidade e seus territórios é um medo singular-coletivo construído.

São as pessoas concretas (personagens do medo) que afetam com mais força as pessoas e coletividades, dando novos sentidos e significados a vida cotidiana e as formas de interagirem, as formas de percepção e vivência de violências. $\mathrm{O}$ medo de ser assaltado ou roubado em casa ou no portão alteram significativamente suas rotinas e ritmos diários: horários de sair e chegar, evitando circular ou transitar à noite pelas ruas sozinhas, espera de filhos ou outro parente no retorno de atividades noturnas, redução nas relações de vizinhança, entre outros; a sociedade vai sofrendo transformações a partir dessas mudanças de rotina, que são formas de defesa ante o medo.

O medo social é o produto da sociedade e das formas violentas, de como são estabelecidas as relações de poder nas relações sociais. É relevante a construção de estratégia e ações para reduzir e combater o nível de violência. Diante da violência visível, idosas são vítimas das doenças invisíveis; os transtornos causados pelo medo excessivo, (no caso, a ansiedade) sendo está desde maior escala de acordo com as fontes de pesquisas.

\section{Ansiedade}

Os transtornos ansiosos compreendem condições comportamentais diferentes entre si, mas comumente provocam sensações subjetivas de desconforto, inquietação, além de desencadear sintomas somáticos. O transtorno de ansiedade refere-se a um fenômeno que, dependendo de sua situação ou intensidade, tornar-se útil patológico, prejudicando a função mental e do corpo.

Em um nível normal, contribui com a fisiologia do corpo responsáveis pela adaptação do organismo, no entanto, quando a ansiedade é excessiva, ela não promove a adaptação, mas desencadeia o fracasso da adaptabilidade cognitivamente, a ansiedade se manifesta das seguintes maneiras, consciente da sensação física de suor, palpitações, inquietação e outros sintomas, nervosismo; fadiga; dificuldade de concentração; irritabilidade; tensão muscular, perturbação do sono (Bittar, Kohlsdorf, 2013). 


\section{Considerações Finais}

O envelhecimento populacional brasileiro explicado sobre a ótica das relações de gênero apresenta manifestações de violência familiar entre idosos, contando com um número significativo de casos, tendo as mulheres as maiores vítimas de tal fenômeno. Outro ponto que também merece atenção é o fato de estarem na terceira idade, onde geralmente se tem pouca ou nenhuma condição de se defender.

Além diante da apontamentos apresentados no estudo, nos casos de violência contra a mulher idosa, observa-se uma subnotificação das denúncias, motivadas em grande parte pelo fato dos agressores, serem familiares mais próximos como cônjuges ou filhos.

A pesquisa possibilitou a visibilidade a questões que afetam de forma direta a vida socioemocional da população feminina idosa onde as demandas do grupo tornaram-se maiores que o estatuto do idoso e as políticas públicas por ser generalistas, já que não atendem de forma eficaz a especificidade desse grupo.

É relevante ressaltar que as sequelas psíquicas para mulheres vítimas de violência existem, e que e ansiedade, depressão são umas das formas de percepção negativa da saúde mental desta população, requerendo formas que possibilitem lidar com esta problemática social, considerando que as mulheres sofrem outras múltiplas formas de violência.

Traçar o perfil dos agressores foi possível, observa-se que o vitimizador geralmente é o filho (sexo masculino), dependente financeiro, com idade inferior a 49 anos, o tipo de principal de violência mais praticado é a física, porém a psicológica e a sexual também são apresentadas, como resultados desse tipo de violência outro fenômeno que se revela é a tentativa de suicídio.

Nesta perspectiva as violências em que as mulheres na terceira idade relacionadas ao seu adoecimento, seja ela físico ou psíquico precisa sair do privado e torna-se público, assim como a publica precisam ser evidenciadas pela a sociedade, as múltiplas formas de violência contra as mulheres na terceira idade não devem ser consideradas normal ou vista como uma cultura de um povo, pois são carregada de preconceito e ódio que podem causam adoecimento e sofrimento psicológico as mulheres na terceira idade.

É importante que se mostre que as mulheres mesmo vítimas de uma sociedade patriarcal, não devem aceitar seu posicionamento dentro do contexto social (como objeto) e busquem seus efetivar seus direitos, principalmente tendo garantias de proteção e cuidado, quando denunciarem os agressores.

Ao longo do tempo pesquisas são realizadas sobre violência contra a mulher, no gargalo destas violências existe a violência contra mulher idosa, sujeitos de grande vulnerabilidade as agressões, a pesquisa buscou pontuar tal fenômeno porém observa-se que como um tema pouco debatido de produções cientificas, mesmo que essa violência venha crescendo, é importante nesse contexto que se apresentem pesquisa mais amplas sobre a violência dos os grupos vulneráveis, grupos invisíveis, pautadas no gênero, e nas possíveis consequências psíquicas.

A longevidade da população feminina fica evidenciado a cada período e a violência causam percas irreparáveis nesta população. Assim é relevante preparar os profissionais para o manejo desses casos, no intuito de garantir que essas mulheres tenham acompanhamento clínico adequado.

Portanto, discutir mais sobre este fenômeno é relevante, apresentar os tipos de violência, agressores e os adoecimentos psicológicos nas mulheres idosas, no intuído de apresentar uma visão global da situação desse grupo é necessário, mesmo que invisíveis, são sujeitos que possuem suas subjetividades, particularidades e valor, merendo uma velhice humanizada e de qualidade. 


\section{Referências}

Almeida, A. V. et al. (2015). A Feminização da Velhice: em foco as características socioeconômicas, pessoais e familiares das idosas e o risco social. Textos \& Contextos, 14, $115-131$.

Almeida, S. A. P., \& Oliveira, R. C. (2013). Envelhecimento digno: inserção da mulher na Universidade Aberta para Terceira Idade. Revista Kairós Gerontologia, 16, 309-323, https://revistas.pucsp.br/index.php/kairos/article/view/18996.

Bittar, D., \& Oliveira, M. (2017). Ansiedade e depressão em mulheres vítimas de violência doméstica. Psicologia Argumento, 31, https://periodicos.pucpr.br/index.php/psicologiaargumento/article/view/20447.

Brasil. (2003). Presidência da República. Lei $n^{o} 10.741$, de $1^{o}$ de outubro de 2003. Dispõe sobre o Estatuto do Idoso e dá outras providências. http://www.planalto.gov.br/ccivil_03/leis/2003/110.741.htm.

Dalgalarrondo, P. (2019). Psicopatologia e semiologia dos transtornos mentais. (3a ed.), Artmed.

Dawalibi, N. W. et al. (2013). Envelhecimento e qualidade de vida: análise da produção científica da SciELO. Estud. Psicol. 30, 393-403. https://www.scielo.br/scielo.php?pid=S0103-166X2013000300009\&script=sci_abstract\&tlng=pt.

Diel, M., \& Barbiani, R. (2018). Violência familiar contra a pessoa idosa: expressões do fenômeno e perspectivas para o seu enfrentamento. Textos \& Contextos. 17, 379-392.

Eckert, C. (2016). A cultura do medo e as tensões do viver a cidade: narrativa e trajetórias de velhos moradores de Porto Alegre. Revista Iluminuras - Banco de Imagens e Efeitos Visuais, 18, p. 2-37. https://evento.ufal.br/anaisreaabanne/gts_download/Suiany\%20Silva\%20de\%20Moraes\%20-\%201020274\%20$\% 203696 \% 20-\% 20$ corrigido.pdf.

Faleiros, V. P., Loureiro, A. M. L., \& Penso, M. A. (2010). O conluio do silêncio: a violência intrafamiliar contra a pessoa idosa. Roca

IBGE. (2018). Número de idosos cresce 18\% em 5 anos e ultrapassa 30 milhões em 2017. https://agenciadenoticias.ibge.gov.br/agencia-noticias/2012agencia-de-noticias/noticias/20980-numero-de-idosos-cresce-18-em-5-anos-e-ultrapassa-30-milhoes-em-2017.

IBGE. (2019). Relatório Disque Direitos Humanos. https://www.gov.br/mdh/pt-br/acesso-a-informacao/ouvidoria/Relatorio_Disque_100_2019_.pdf.

Knapp, P., \& Caminha, R. (2003). Terapia cognitiva do transtorno de estresse pós-traumático. Revista Brasileira e Psiquiatria, São Paulo, v. 25. http://www.scielo.br/scielo.php?script=sci_abstract\&pid=S151644462003000500008\&lng=pt\&tlng=pt.

Matos N. M. et al. (2019). Perfil do agressor de pessoas idosas atendidas em um centro de referência em geriatria e gerontologia do Distrito Federal, Brasil. Rev. Bras. Geriatr. Gerontol. 22, n,5.

Maximiano-Barreto, M. A. (2019). A feminização da velhice: uma abordagem biopsicossocial do fenômeno. Interfaces Científicas Humanas e Sociais. 8 , 239 $-252$

Mota, M. L. (2017). Violência contra as mulheres e saúde mental: silenciamentos e invisibilidades do sofrimento de usuárias da atenção primária à saúde em Recife.

Neri, A. L. (2016). Desenvolvimento e envelhecimento, perspectivas biológicas, psicológicas e sociológicas. Papirus.

Paulo, E. C. T., Alves, R. M., Machado, A. K. C. (2019). Os impactos da violência psicológica na saúde mental da pessoa idosa. [S.I]. CESAC.

Ploner, K. S., Hoffmann, R. M., Baldissera. (2014). Violência contra idosos: análise das denúncias e seu atendimento no Creas. RBCEH, 11, 141-151

Rocha, C. (2017). Violência contra a mulher idosa. Consultoria legislativa. Segurança Pública e Defesa Nacional.

Silva, C. F. S.S., Dias, C. M. S. B. (2016). Violência contra idosos: perfil sociodemográfico dos familiares agressores, tipos de violência impetrada e motivações para sua ocorrência. Revista Eletrônica Gestão \& Saúde. 7, 563-581. 